\title{
Early Intervention IN PSYCHIATRY
}

The impact of communicating personal mental ill-health risk: A randomized controlled non-inferiority trial

\begin{tabular}{|r|l|}
\hline Journal: & Early Intervention in Psychiatry \\
\hline Manuscript ID & EIP-2020-025.R2 \\
\hline Manuscript Type: & Original Article \\
\hline Date Submitted by the & 22-Jul-2020 \\
\hline Complete List of Authors: & $\begin{array}{l}\text { Choi, Isabella; The University of Sydney, Faculty of Health and Medicine, } \\
\text { Brain and Mind Centre } \\
\text { Ho, Nicholas; The University of Sydney, Brain and Mind Centre } \\
\text { Morris, Richard; The University of Sydney, Faculty of Medicine and } \\
\text { Health, Centre for Translational Data Science } \\
\text { Harvey, Samuel; University of New South Wales, Black Dog Institute } \\
\text { Calvo, Rafael; Imperial College London, Faculty of Engineering, Dyson } \\
\text { School of Design Engineering } \\
\text { Glozier, Nicholas; The University of Sydney, Faculty of Health and } \\
\text { Medicine, Brain and Mind Centre }\end{array}$ \\
\hline Keywords: & $\begin{array}{l}\text { risk communication, mental health, non-inferiority trial, psychological } \\
\text { distress, risk algorithm }\end{array}$ \\
\hline
\end{tabular}

\section{SCHOLARONE"


The impact of communicating personal mental ill-health risk: A randomized controlled non-inferiority trial

Running title: Communicating personal mental ill-health risk

\section{Word count: 3249}

Isabella Choi ${ }^{1}$

Nicholas $\mathrm{Ho}^{1}$

Richard Morris ${ }^{2}$

Samuel B Harvey ${ }^{3}$

Rafael A Calvo 4

Nicholas Glozier ${ }^{1}$

${ }^{1}$ Central Clinical School, Faculty of Medicine and Health, Brain and Mind Centre, University of Sydney, Sydney, Australia

${ }^{2}$ Central Clinical School, Faculty of Medicine and Health, Centre for Translational Data Science, University of Sydney, Sydney, Australia

${ }^{3}$ Black Dog Institute, University of New South Wales, Sydney, Australia

${ }^{4}$ Faculty of Engineering, Dyson School of Design Engineering, Imperial College London, United Kingdom

Corresponding author:

Isabella Choi, Brain and Mind Centre, 94 Mallett Street, University of Sydney, Sydney, Australia

Email: isabella.choi@sydney.edu.au 


\begin{abstract}
(250)
Aim: Risk algorithms predicting personal mental ill-health will form an important component of digital and personalised preventive interventions, yet it is unknown whether informing people of personal risk may cause unintended harm. This trial evaluated the comparative effect of communicating personal mental ill-health risk profileson psychological distress.

Methods: Australian participants usinga mood-monitoring app were randomly allocated to receiving their current personal mental ill-health risk profile $(n=119)$, their achievable personal risk profile $(n=118)$ or to a control group $(n=118)$ in which no risk information was communicated, in a non-inferiority trial design. The primary outcome was psychological distress at four-weeks as assessed on the Kessler Psychological Distress Scale.

Results: There was high attrition in the trial with $64 \%$ of data missing at follow up. Perprotocol (completer) analysis found that the lower bounds of the confidence intervals of the estimated mean change of the current risk $(m=0.19,95 \% \mathrm{Cl}:-2.59-2.98)$ and achievable risk $(m=-0.09,95 \% \mathrm{Cl}:-2.84-2.66)$ groups were within the non-inferiority margin of the control group's mean at follow up. Supplementary intention-to-treat analysis using Multivariate Imputation by Chained Equations (MICE) found that 98/100 imputed datasets of the current risk profile group, and all imputed datasets of the achievable risk profile group showed noninferiority to the control group.

Conclusions: This study provides preliminarysupport thatproviding personal mental health risk profiles does not lead to unacceptable worsening of distress compared to no risk feedback, although this needs to be replicated in a fully powered RCT.
\end{abstract}

\title{
Keywords:
}

Risk communication, mental health, non-inferiority trial, psychological distress, risk algorithm 


\section{Introduction}

Depression and anxiety are leading causes of disability(Whiteford et al., 2013), and preventive interventions are needed to reduce disease burden (Andrews, Sanderson, Slade, \& Issakidis, 2000). Identifying at-risk individuals using risk models to deliver targeted lifestyle or drug interventions have long been used in the prevention of cardiovascular disease(Damen et al., 2016) and diabetes (Noble, Mathur, Dent, Meads, \& Greenhalgh, 2011). Severalrisk algorithms have been developed and validated to predict mental ill-health (Fernandez et al., 2017; King et al., 2013; King et al., 2011; King, Walker, Levy, \& et al., 2008; Wang et al., 2013; Wang, Patten, et al., 2014; Wang, Sareen, et al., 2014), with preliminary support thatinforming patients of their personal risk for depression and their modifiable risk factors with guidance on how to alter behavior, reduces depression incidence(Bellón et al., 2016).

Risk algorithms can be readily incorporated into digital mental health interventions to deliver targeted prevention in an anonymous,cost-effective manner to wide audiences(Deady et al., 2020).Although potentially beneficial, it is unclear whether communicatingthis risk may lead to unintended harms, especially when delivered without human support. Primary care patients generally had a positive attitude towards knowing their personal depression risk, but were concernedsuch information may cause alarmin others(Bellón et al., 2014). Similar concerns have been raised about communicating personal risk of physical diseases, although any adverse effects found are only short-term (less than 1 month)(Collins, Lopez, \& Marteau, 2011; Shaw, Abrams, \& Marteau, 1999). Onesystematic review reported that informing individuals about their risk of a range of treatable and untreatable physical diseases led to increased short-term distress among those with heightened risk, but no impact on those with low risk (Shaw et al., 1999). Similarlya meta-analysis found that screeningpositive for physical diseases led to a marginal short term increase in depression but no increase in anxiety (Collins et al., 2011). However, no study has experimentally examined the effect of communicating personal risk of mental ill-health on psychological distress.

Understanding one's risk of mental ill-health is considered essential to engaging in prevention. The Health Belief Modelidentifies perceived susceptibility as a key component of preventive health behaviour change (Janz \& Becker, 1984), arguing that people are more motivated to engage in prevention behaviours if they believe they are at higher risk of a negative health outcome. In addition, patientsreport that apart from knowing their personal 
risk, it was important to be provided with information on how toreduce their risk(Bellón et al., 2014). Our online survey found that peoplewere interested in knowing their personalmental ill-health risk level,modifiablerisk factors, and by how much their risk could be reduced (Choi et al., in preparation). However, we do not know if communicatingsuch personal risk reduction has any effect on psychological distress, accuracy of risk perception, and influence on behavior.

This study aimed to examine the impact ofcommunicating personal mental ill-health risk online on prolongedpsychological distress. A non-inferiority trial was developed to test the hypothesis that communicating personal risk would not lead to unacceptable deterioration in distress compared to not receiving risk information. The secondary objective was to examine the effects of personal risk profile formats on accuracy of perceived risk and behavior by comparing the effect of two personal risk profile formats (personal risk with and without lowest possible risk).

\section{Method:}

\subsection{Design:}

Mindtrack is a mood-monitoring app with a mental ill-health risk assessment component. Embedded in the app was information and consent enabling access to a randomized controlled non-inferiority trialcomparing communicating1) current mental illhealth risk profile, 2) the current risk profile + "achievable" risk profile with modifiable risks, and 3) no risk information (control). The study was approved by the Human Research Ethics Committee (HREC) of the University of Sydney (project number: 2017/728) and registered as ACTRN12617001390370.

\subsection{Participants and recruitment:}

Participants were recruited online using Facebook advertisements and shared social media posts from partners (e.g. Black Dog Institute, beyondblue) from December 2017 to March 2018. An industry organisation also promoted the app to employees via email communications. The promotional material directed interested people to download the freeMindtrack app from Apple or Google Play app stores. People were eligible to participate if they were aged between 18 years and 70 years, were fluent in English, were resident in Australia, hada smartphone and a valid mobile number.

\subsection{Procedures and randomisation:}


Participants provided consent in the Mindtrack app and proceeded tobaseline measures includingpsychological distress and the risk assessment consisting of items from a validated, gender specific risk algorithm to predict mental ill-health among working Australian adults (Fernandez et al., 2017) (Table 1). Participants were thenrandomisedwithin the app using an automatic random allocation sequence to receiveone of two active interventions or the control in a 1:1:1 ratio, as described below. Participants and researchers were not blinded to group assignment.

All participants were encouraged to use Mindtrack to track their mood and complete weekly measures on distress. Participants received a sms and/or phone reminder to complete the endpoint measures at four weeks follow up using an online survey. The app automatically recorded the number of times it was opened and number of moods logged.

\subsection{Interventions:}

2.4.1. Current mental ill-health risk profile:

Participantsreceived their personal risk estimate of developing mental ill-health within the next 12 months (based on the risk algorithm)immediately after completing the baseline assessment. A screen with an icon array displayed their personal numerical risk, along with a text description " $X X$ out of 100 people with your risk factors are likely to become distressed within the next year" (see Figure 1a).

\subsubsection{Achievable mental ill-health risk profile:}

In addition toreceiving their personal risk estimate as above (Figure 1a), this groupwere shown their "achievable risk" on the next screen (Figure 1b), in which the icon array displayed the lowest possible risk estimate for that individual, based on the targets being met for all the modifiablerisk factors (Table 1). The difference in the risk estimate was shown in a lighter green colour to indicate the reduced risk, with the accompanying text "Many risk factors are changeable. You could lower your risk to XX out of 100 by improving your mental fitness". The screen also displayed their top five modifiable risk factors, each accompanied with a simple message indicating ways they could reduce their risk, e.g. exercising less than three times a week was accompanied by: "Regular exercise is more than just physically good for you, it also reduces stress and your risk of depression and anxiety. Whether it's a walk, a ride or climbing the stairs, how could you add a bit of exercise to your week?".

\subsubsection{Controls:}


The control group were given the standard Mindtrack app and received risk feedback after the follow up.

\subsection{Measures}

\subsubsection{Primary outcome: Psychological distress}

The Kessler Psychological Distress Scale (K10) is a validated measure of nonspecific psychological distress(Furukawa, Kessler, Slade, \& Andrews, 2003) with demonstrated sensitivity to change in an Australian sample(Perini, Slade, \& Andrews, 2006). Instructions of the K10 were changed to refer to the past week as it was administered weekly in this study. The internal consistency of the $\mathrm{K} 10$ was $\alpha=.92$.

\subsubsection{Secondary outcome: Perceived risk accuracy}

At follow up, participants were asked about their perceived risk of developing a mental health problem within the next year ranging from 0 (certain not to happen) and 100 (certain will happen). To examine accuracy of perceived risk, the participant's perceived risk was subtracted from their actual risk estimate. We recoded the difference into a categorical variable, with $<-10 \%$ indicating underestimation, $>10 \%$ indicating overestimation, and accurate if $-10 \% \leq D \leq 10 \%$, in accordance with previous studies(Rimer et al., 2002). Participants were asked "Have you sought help for a mental health problem from any of the sources in the past month (apart from engaging in this app)?" at follow up.

\subsection{Statistical methods}

Power calculations were based on a non-inferiority parallel arm trial design. The noninferiority margin of the mean difference of the primary outcome measure $\mathrm{K} 10$ was set at 4.6 points; the difference between the mean Australian score for people without ( $M=14.5$, $S D=9.4)$ and with a mental disorder $(M=19.1)$ in the 2007 National Survey of Mental Health and Wellbeing(Slade, Grove, \& Burgess, 2011). Test criterion for non-inferiority was that the lower bounds of the $95 \%$ confidence intervals $(\mathrm{Cl})$ of the mean $\mathrm{K} 10$ change score for the risk profile groups should fall within 4.6 points of the control group's mean at four weeks follow up. Considering this predefined non-inferiority margin, 68 participants per group were required to determinenon-inferiority with a power of $80 \%$ using a one-sided Student's t-test for independent samples at $2.5 \%$ type I error. A total of 340 participants need to be recruited for estimated $40 \%$ attrition.

In non-inferiority trials, intent-to-treat (ITT) analyses have been criticized as anticonservative because they typically decrease the differences between groups and favour 
the null hypothesis, increasing the likelihood of concluding non-inferiority(Sanchez \& Chen, 2006). Conversely, per-protocol (PP) analyses do not consider the impact of dropouts, and downplay the influence of continuing participants being more likely to be those who respond. CONSORT guidelines state there is greater confidence if both ITT and PP analyses support non-inferiority (Piaggio et al., 2006). Hence, in this study, per-protocol analysis was performed with complete cases, supplemented by ITT analysis, in which 100 imputed datasets were synthesised with multiple imputation (Azur, Stuart, Frangakis, \& Leaf, 2011) using MICE (Multivariate Imputation by Chained Equations) (van Buuren \& GroothuisOudshoorn, 2011) where missing values for the change in total distress scores from baseline to follow up were imputed with predictive mean matching (Roderick, 1988). Plausibility of the imputed values were inspected visually and the mean endpoint distress scores and its associated $95 \% \mathrm{Cl}$ were calculated for each group for each imputed dataset.

Statistical analyses were conducted using IBM SPSS Statistics version 24. ANOVA, t-tests, and chi-square analyses were used to estimate between-group differences in demographics and baseline measures, and for attrition. Mean distress change scores from baseline to follow up were calculated for each group. Thesewereanalysed usingANCOVA controlling for baseline $\mathrm{K} 10$ score and age, comparing the current risk profile group to controls, and the achievable risk profile group to controls, and computed to find the lower bounds of the $95 \%$ confidence interval to establish non-inferiority. ANOVA and chi-square tests were used to compare groups over time and for the secondary outcomes.

\section{Results:}

684 participants enrolled in the study but 329 did not meet inclusion criteria (see Figure 2). 355 participants were randomised to one of three feedback interventions: the current mental ill-health risk profile $(n=119)$, achievable mental ill-health risk profile $(n=118)$, or control $(n=118)$.

Majority of participants were women (68\%) with a mean age of 31.9 years $(S D=12.6)$. About $80 \%$ self-reported a period of mental ill-health in the past two years and $79 \%$ had a high risk of mental ill-health in the next 12 months, compared to $12 \%$ in a nationally representative sample (Fernandez et al., 2017). There was no significant between group differences on any demographic or clinical baseline characteristics or risk scores (Table 2).

\subsection{Attrition}


The 4 week follow up K10 score was missing in 80/118 of the control group (67.8\%), $75 / 119$ of the current risk group (63.0\%) and $71 / 118$ of the achievable risk group $(60.2 \%)$. There was no differential in attrition between arms of the trial $\left(X^{2}=1.52\right.$, $p=.469)$. Overall those who remained in the trial were significantly older than those who dropped out $\left(\mathrm{t}_{1,353}=-2.67, p=.008\right)$. There was no other significant association of baseline demographic or clinical measures with attrition (Supplementary Table 1).The mean endpoint distress scores and the density plot forper-protocol, last-observation carried forward (LOCF), and as predicted by MICE are similar (Figure 3).

\subsection{Change in distress over time}

The per-protocol (completer)mean K10 score at baseline was 26.30 (SD=8.61), and mean score at 4 -week follow up was $24.43(S D=8.29)$. Figure 4 presents the change of K10 scores over the four weeks across the groups. Participants showed a significant reduction in distress scores from baseline to Week $1\left(F_{1,198}=27.35, p<.0005\right)$, with no significant difference between groups ( $p>.05)$, and from baseline to four weeks follow up $\left(F_{1,126}\right.$ $=18.522, p<.0005)$, again with no group differences $(p>.05)$.

\subsection{Non-inferioritymean scorechange in psychological distress}

Per-protocolanalysis controlling for age and baseline K10 scores confirmed that the mean K10 score change was not significantly different between groups $\left(F_{2,124}=.024\right.$, $p=.976$ )(Table 3). The estimated difference in mean $\mathrm{K} 10$ change score between the current risk profile group and control group was $0.19(95 \% \mathrm{Cl}-2.59-2.98)(p=.891)$. This equates to an effect size of 0.04 , and a total sample of 19,328 would have been required to showthat thiseffect size was 'statistically significant' at alpha $2.5 \%$ and $80 \%$ power. The estimated difference in mean $\mathrm{K} 10$ change score between the achievable risk profile group and controls was even less;-0.09(95\% Cl -2.84-2.66) ( $p=.946)$, an effect size of 0.01 , only detectable with a sample size of 193,480 at $2.5 \%$ alpha and $80 \%$ power. Even with this relatively small sample, the lower bounds of our obtained confidence intervals for the mean differences in distress were within the predefined non-inferiority margin (4.6 points), suggesting that the current risk and achievable risk groups were non-inferior to controls. Five participants(11\%) in the current risk profile group, three $(6.4 \%)$ in the achievable risk profile group, and four $(10.5 \%)$ in the control group had higher change scores than the predefined non-inferiority margin.

For the ITT analysis, 98/100 imputed datasets showed non-inferiority of the current risk profile group to the control group as the lower bounds of the $95 \% \mathrm{Cl}$ of the mean change in total $\mathrm{K} 10$ score for the current risk group was within the predefined non-inferiority margin. 
For the achievable risk group, all imputed datasets were within the predefined non-inferiority margin.

\subsection{Perceived riskaccuracy}

The intervention groups differed significantly on the accuracy of their perceived risk $\left(x^{2}=12.43, p=.014\right)$ (Table 4$)$. Half of the current risk group correctly perceived their risk level, while the achievable risk group were equally likely to be accurate or overestimate or underestimate risk, and the control group tended to underestimate their risk.

\subsection{Help-seeking}

Most participants $(81 \%)$ sought help from formal or informal sources during the four weeks of using the app with no significant difference between groups $(p>.05)$. About half $(47 \%)$ reported seeking help from a health professional (mental health professional, GP), $60 \%$ reported seeking informal assistance (family, friend, minister), while $26 \%$ sought help from helplines or online.

\subsection{App engagement}

Participants opened the app an average 5.21 times $(S D=6.94$; range 1-55) and logged 7.25 moods ( $S D=12.75$; range $0-88$ ) over 4 weeks. There was no significant difference between groups on these engagement metrics (all $p s>.05$ )

\section{Discussion:}

This is thefirst study empirically evaluatingwhether communicating personal mental ill-health risk profile has a potentiallyunintended impact on prolonged psychological distress. Trial attrition was higher than expected at about $64 \%$, and while this is not unusual given online app use and fully automated trial(Geraghty, Torres, Leykin, Perez-Stable, \& Munoz, 2013)(Eysenbach, 2005), the study was underpowered and results should be interpreted with caution. The per-protocol analysissupported that providing personal mental ill-health risk profiles did not lead to unacceptable worsening of distress compared to not communicating risk. The supplementary ITT analysis with MICE, while not ideal given the high attrition (Jakobsen, Gluud, Wetterslev, \& Winkel, 2017), also showed support for noninferiority.

In contrast to the small but significant short term increases in distress among individualsinformed of their riskfor physical diseases (Collins et al., 2011; Shaw et al., 1999), 
psychological distress improved within the first week of receiving personal mental ill-health risk feedback. There are several possible explanations. First, this sample displayed above average levels of distress at baseline and were at high risk of developing mental ill-health according to the risk model. Providing this relatively unwell and high-risk group with risk feedback might not cause further distress because of ceiling effects. The high attrition and high representation of high-risk individuals precluded a sensitivity analysis comparing low versus high risk individuals leaving open the question of the impact in low risk groups. Second, risk of physical health problems is often communicated to people free of disease and being informed of high risk of serious disease can lead to distress. As most of our sample have had previous mental ill-health, it is possible they were less perturbed by the risk feedback. Participants may also hold positive beliefs that mental ill-health can be prevented (Jorm, Morgan, \& Wright, 2010; Schomerus, Angermeyer, Matschinger, \& RiedelHeller, 2008; Yap, Reavley, \& Jorm, 2012), and felt they could reduce their (often high) risk. Third, it is possible that participants in the intervention groups may not have registered their risk seriously because of the nature of risk being presented in an app and there was lack of information about the validity of the risk algorithm.

Although others have reported that patients want be provided with risk reduction information (Bellón et al., 2014), we found no added impact of communicating this potential risk reduction. Communicating risk did not lead to higher help-seeking or app engagement among participants. This is similar finding to other studies which found providing online feedback with mental health screening does not facilitate formal help seeking (Batterham, Calear, Sunderland, Carragher, \& Brewer, 2016).

Despite efforts to accurately communicate risk using easily understandable natural frequencies and pictograms(Waldron, van der Weijden, Ludt, Gallacher, \& Elwyn, 2011), only half of the current risk group were accurate in their risk estimate. Nonetheless this provides encouraging support that communicating personal risk can improve perceived risk accuracy, as a recent study found that high risk people tended to overestimate their risk (Wang et al., 2020).A limitation in asking participants to rate their perceived risk at fourweeks follow up may have been measuring their recall rather than accurate understanding of risk. Further, the mixed results in the achievable risk group may reflect they have confused their "currentrisk" and "achievable risk" in their responses. Changing behaviour might require challenging this risk-perception gap as in motivational interviewing. Help-seeking too was assessed only at the follow-up, so it is unclear whether this was a proactive "treatmentseeking" sample, which may have biased study findings. 
This study provides preliminary support that communicating personal mental illhealth risk profiles does not havemajor adverse effects on prolonged distress, even when communicated online without personal contact, suggesting there is potential for it to be safely incorporated in digital prevention interventions for common mental disorders. While both the per-protocol and ITT analysis supported aninference of non-inferiority, the high attrition rate meant that these results need to be interpreted with caution, and findings need to be replicated in a fully powered RCTin order to draw confident conclusions that communicating personal mental ill-health risk does not cause prolonged distress. Although our sample was relatively unwell and high risk compared to the general population, this is the exact target group for selective prevention interventions.Future research is neededto explore the impact of communicating risk on low-risk people, and to explore how to engage and motivate people to manage and reduce their risk once this is communicated. The COVID-19 pandemic has accelerated digital health service development and provision(Wind, Rijkeboer, Andersson, \& Riper, 2020). Understanding how best to implement and possible negative effects will be increasingly important.

\section{Acknowledgements:}

Conflict of interest statement: This study was developed in partnership with beyondblue with donations from the Movember Foundation. The authors confirm that there are no known conflicts of interest associated with this publication.

\section{Data statement}

The data that support the findings of this study are available from the corresponding author upon reasonable request. 


\section{References:}

Andrews, G., Sanderson, K., Slade, T., \& Issakidis, C. (2000). Why does the burden of disease persist? Relating the burden of anxiety and depression to effectiveness of treatment. Bulletin of the World Health Organization, 78, 446-454.

Azur, M. J., Stuart, E. A., Frangakis, C., \& Leaf, P. J. (2011). Multiple imputation by chained equations: what is it and how does it work? International Journal of Methods in Psychiatric Research, 20(1), 40-49. doi:10.1002/mpr.329

Batterham, P. J., Calear, A. L., Sunderland, M., Carragher, N., \& Brewer, J. L. (2016). Online screening and feedback to increase help-seeking for mental health problems: population-based randomised controlled trial. British Journal of Psychiatry Open, 2, 67-73. doi:10.1192/bjpo.bp.115.001552

Bellón, J. Á., Conejo-Cerón, S., Moreno-Peral, P., King, M., Nazareth, I., Martín-Pérez, C., . . de Dios Luna, J. (2016). Intervention to prevent major depression in primary care: A cluster randomized trial preventing major depression in primary care. Annals of Internal Medicine, 164, 656-665. doi:10.7326/M14-2653

Bellón, J. Á., Moreno-Peral, P., Moreno-Küstner, B., Motrico, E., Aiarzagüena, J. M., Fernández, A., . . . Amezcua, M. (2014). Patients Opinions about Knowing Their Risk for Depression and What to Do about It. The PredictD-Qualitative Study. PLoS ONE, 9, e92008. doi:10.1371/journal.pone.0092008

Collins, R. E., Lopez, L. M., \& Marteau, T. M. (2011). Emotional impact of screening: a systematic review and meta-analysis. BMC Public Health, 11(1), 1-10. doi:10.1186/1471-2458-11-603

Damen, J. A. A. G., Hooft, L., Schuit, E., Debray, T. P. A., Collins, G. S., Tzoulaki, I., . . Moons, K. G. M. (2016). Prediction models for cardiovascular disease risk in the general population: systematic review. BMJ, 353. doi:10.1136/bmj.i2416

Deady, M., Glozier, N., Calvo, R., Johnston, D., Mackinnon, A., Milne, D., ... Harvey, S. B. (2020). Preventing depression using a smartphone app: a randomized controlled trial. Psychological Medicine, 1-10. doi:10.1017/S0033291720002081

Eysenbach, G. (2005). The Law of Attrition. J Med Internet Res, 7(1), e11. doi:10.2196/jmir.7.1.e11

Fernandez, A., Salvador-Carulla, L., Choi, I., Calvo, R., Harvey, S. B., \& Glozier, N. (2017). Development and validation of a prediction algorithm for the onset of common mental disorders in a working population. Australian \& New Zealand Journal of Psychiatry, 52. doi:10.1177/0004867417704506

Furukawa, T. A., Kessler, R. C., Slade, T., \& Andrews, G. (2003). The performance of the K6 and K10 screening scales for psychological distress in the Australian National Survey of Mental Health and Well-Being. Psychological Medicine, 33, 357-362. doi:10.1017/S0033291702006700

Geraghty, A. W., Torres, L. D., Leykin, Y., Perez-Stable, E. J., \& Munoz, R. F. (2013). Understanding attrition from international Internet health interventions: a step towards global eHealth. Health Promotion International, 28, 442-452. doi:10.1093/heapro/das029

Jakobsen, J. C., Gluud, C., Wetterslev, J., \& Winkel, P. (2017). When and how should multiple imputation be used for handling missing data in randomised clinical trials - a practical guide with flowcharts. BMC Medical Research Methodology, 17, 162. doi:10.1186/s12874-0170442-1

Janz, N. K., \& Becker, M. H. (1984). The Health Belief Model: A Decade Later. Health Education Quarterly, 11, 1-47. doi:10.1177/109019818401100101

Jorm, A. F., Morgan, A. J., \& Wright, A. (2010). Actions that young people can take to prevent depression, anxiety and psychosis: Beliefs of health professionals and young people. Journal of Affective Disorders, 126(1), 278-281. doi:10.1016/j.jad.2010.03.011

King, M., Bottomley, C., Bellón-Saameño, J., Torres-Gonzalez, F., Svab, I., Rotar, D., . . Nazareth, I. (2013). Predicting onset of major depression in general practice attendees in Europe: extending the application of the predictD risk algorithm from 12 to 24 months. Psychological Medicine, 43, 1929-1939. doi:10.1017/\$0033291712002693 
King, M., Bottomley, C., Bellon-Saameño, J. A., Torres-Gonzalez, F., Svab, I., Rifel, J., . . Nazareth, I. (2011). An international risk prediction algorithm for the onset of generalized anxiety and panic syndromes in general practice attendees: predictA. Psychological Medicine, 41, 16251639. doi:10.1017/S0033291710002400

King, M., Walker, C., Levy, G., \& et al. (2008). Development and validation of an international risk prediction algorithm for episodes of major depression in general practice attendees: The predictd study. Archives of General Psychiatry, 65, 1368-1376. doi:10.1001/archpsyc.65.12.1368

Noble, D., Mathur, R., Dent, T., Meads, C., \& Greenhalgh, T. (2011). Risk models and scores for type 2 diabetes: systematic review. BMJ, 343. doi:10.1136/bmj.d7163

Perini, S. J., Slade, T., \& Andrews, G. (2006). Generic effectiveness measures: Sensitivity to symptom change in anxiety disorders. Journal of Affective Disorders, 90, 123-130. doi:10.1016/j.jad.2005.10.011

Piaggio, G., Elbourne, D. R., Altman, D. G., Pocock, S. J., Evans, S. W., \& f, C. G. (2006). Reporting of noninferiority and equivalence randomized trials: An extension of the consort statement. JAMA, 295, 1152-1160. doi:10.1001/jama.295.10.1152

Rimer, B. K., Halabi, S., Sugg Skinner, C., Lipkus, I. M., Strigo, T. S., Kaplan, E. B., \& Samsa, G. P. (2002). Effects of a mammography decision-making intervention at 12 and 24 months. American Journal of Preventive Medicine, 22, 247-257. doi:10.1016/S0749-3797(02)00417-8

Roderick, J. A. L. (1988). Missing-Data Adjustments in Large Surveys. Journal of Business \& Economic Statistics, 6(3), 287-296. doi:10.2307/1391878

Sanchez, M. M., \& Chen, X. (2006). Choosing the analysis population in non-inferiority studies: per protocol or intent-to-treat. Statistics in Medicine, 25, 1169-1181. doi:10.1002/sim.2244

Schomerus, G., Angermeyer, M. C., Matschinger, H., \& Riedel-Heller, S. G. (2008). Public attitudes towards prevention of depression. Journal of Affective Disorders, 106, 257-263. doi:10.1016/j.jad.2007.06.013

Shaw, C., Abrams, K., \& Marteau, T. M. (1999). Psychological impact of predicting individuals' risks of illness: a systematic review. Social Science \& Medicine, 49, 1571-1598. doi:10.1016/S02779536(99)00244-0

Slade, T., Grove, R., \& Burgess, P. (2011). Kessler psychological distress scale: normative data from the 2007 Australian National Survey of Mental Health and Wellbeing. Australian and New Zealand Journal of Psychiatry, 45, 308-316. doi:10.3109/00048674.2010.543653

van Buuren, S., \& Groothuis-Oudshoorn, K. (2011). mice: Multivariate Imputation by Chained Equations in R. 2011, 45(3), 67. doi:10.18637/jss.v045.i03

Waldron, C.-A., van der Weijden, T., Ludt, S., Gallacher, J., \& Elwyn, G. (2011). What are effective strategies to communicate cardiovascular risk information to patients? A systematic review. Patient Education and Counseling, 82, 169-181. doi:10.1016/j.pec.2010.04.014

Wang, J., Manuel, D., Williams, J., Schmitz, N., Gilmour, H., Patten, S., . . Birney, A. (2013). Development and validation of prediction algorithms for major depressive episode in the general population. Journal of Affective Disorders, 151(1), 39-45. doi:10.1016/j.jad.2013.05.045

Wang, J., Patten, S., Sareen, J., Bolton, J., Schmitz, N., \& MacQueen, G. (2014). Development and validation of a prediction algorithm for use by health professionals in prediction of recurrence of major depression. Depression and Anxiety, 31, 451-457. doi:10.1002/da.22215

Wang, J., Sareen, J., Patten, S., Bolton, J., Schmitz, N., \& Birney, A. (2014). A prediction algorithm for first onset of major depression in the general population: development and validation. Journal of Epidemiology and Community Health. doi:10.1136/jech-2013-202845

Wang, J., Smail-Crevier, R., Nannarone, M., Manuel, D., MacQueen, G., Patten, S. B., . . Schmitz, N. (2020). The accuracy of depression risk perception in high risk Canadians. Journal of Affective Disorders, 265, 410-415. doi:10.1016/j.jad.2020.01.099 
Whiteford, H. A., Degenhardt, L., Rehm, J., Baxter, A. J., Ferrari, A. J., Erskine, H. E., . . Vos, T. (2013). Global burden of disease attributable to mental and substance use disorders: findings from the Global Burden of Disease Study 2010. The Lancet, 382, 1575-1586. doi:10.1016/S01406736(13)61611-6

Wind, T. R., Rijkeboer, M., Andersson, G., \& Riper, H. (2020). The COVID-19 pandemic: The 'black swan' for mental health care and a turning point for e-health. Internet Interventions, 20, 100317. doi:10.1016/j.invent.2020.100317

Yap, M. B. H., Reavley, N., \& Jorm, A. F. (2012). Young people's beliefs about preventive strategies for mental disorders: Findings from two Australian national surveys of youth. Journal of Affective Disorders, 136(3), 940-947. doi:10.1016/j.jad.2011.09.003 


\section{- $\square$} (3) ${ }^{4 G} 4$ 然 $12: 34$

○्

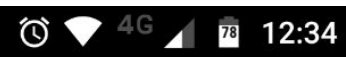

Risk Feedback

\section{Your risk}

Based on your risk factors, 23 out of 100 people like you will become distressed within the next year.

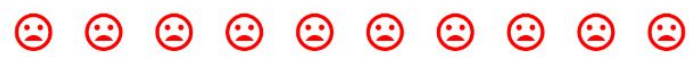

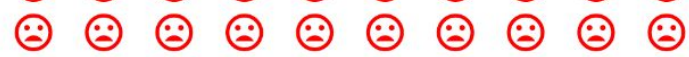

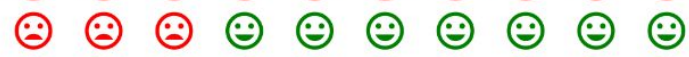

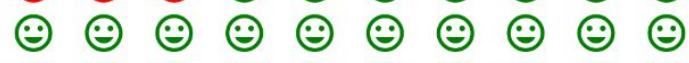

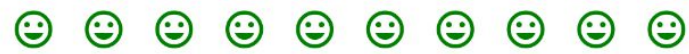

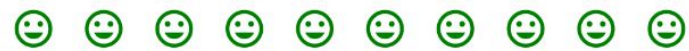

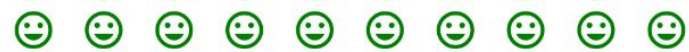

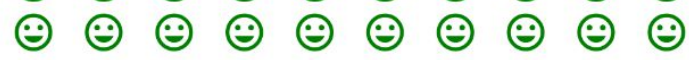

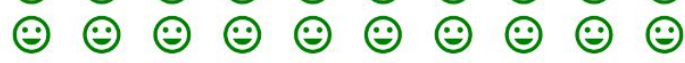

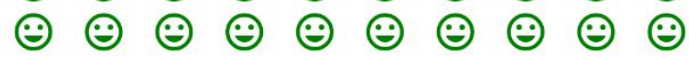

$\leftarrow$

Risk Feedback

\section{Achievable risk}

Many risk factors are changeable.

You could lower your risk to 16 out of 100 by improving your mental fitness.

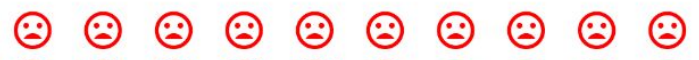

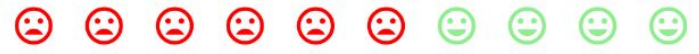

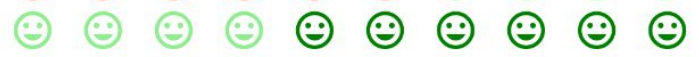

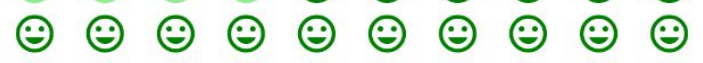

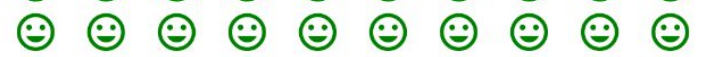

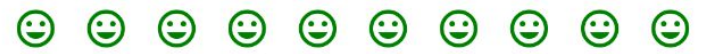

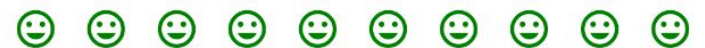

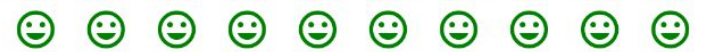

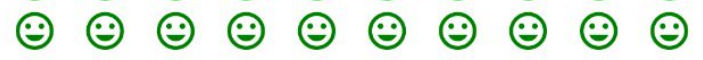

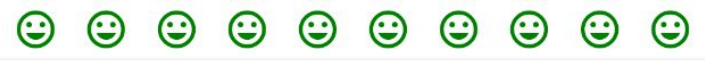
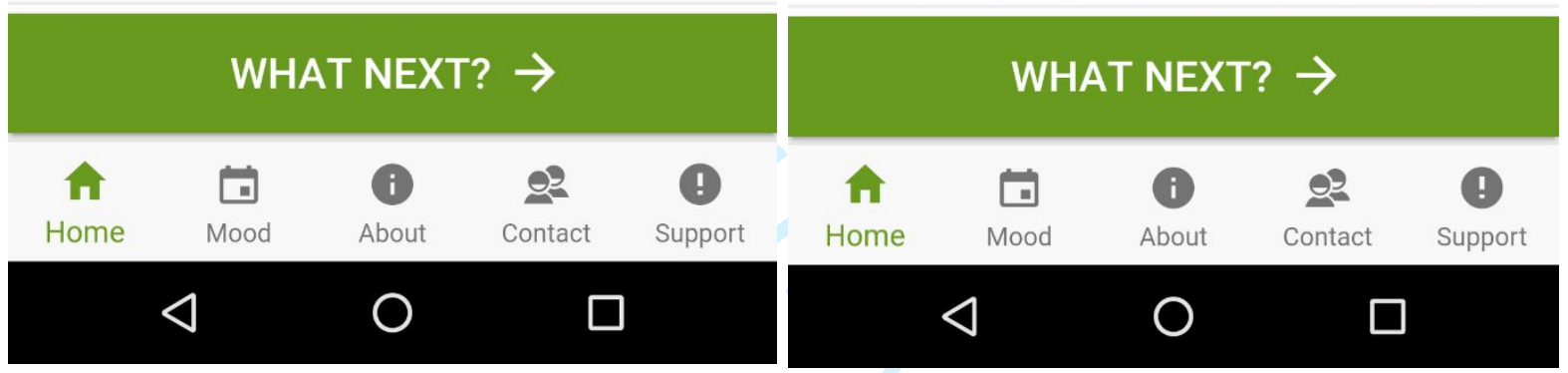

a) Current risk

b) Achievable risk

Figure 1. Example personal mental ill-health risk profile 


\section{CONSORT 2010 Flow Diagram}

\section{Enrollment}

\section{Allocation}
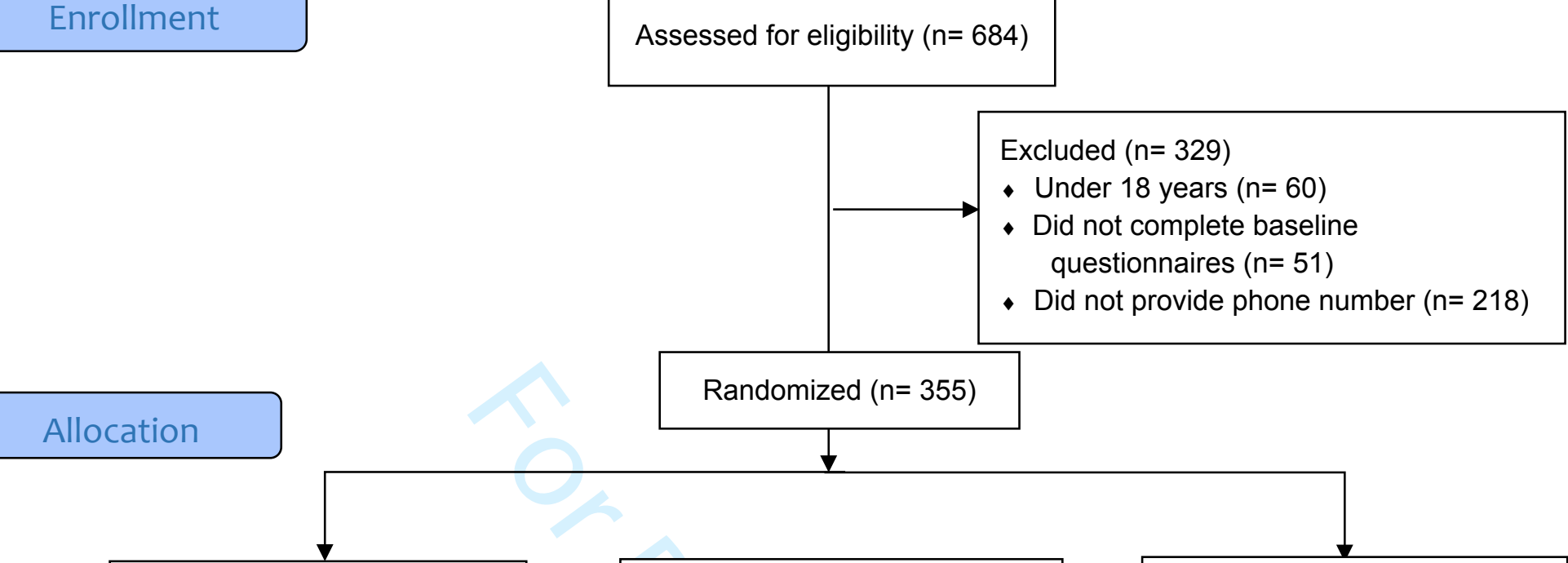

Allocated to control $(n=118)$

\section{Follow-Up}

Lost to follow-up $(n=80)$

\section{Analysis}

Analysed per-protocol $(n=38)$

Analysed intention-to-treat $(n=118)$

Figure 2. Participant flow.

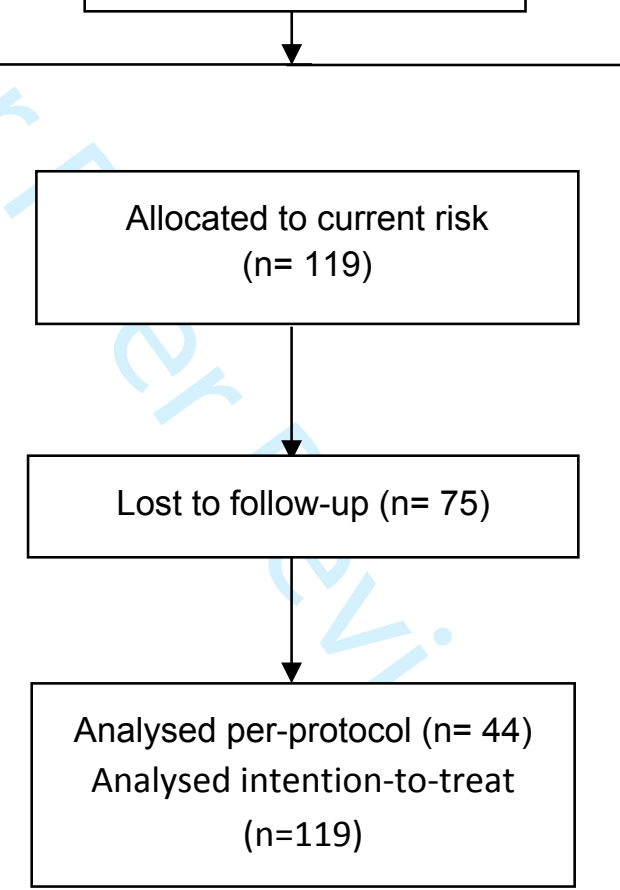

Allocated to achievable risk $(n=118)$

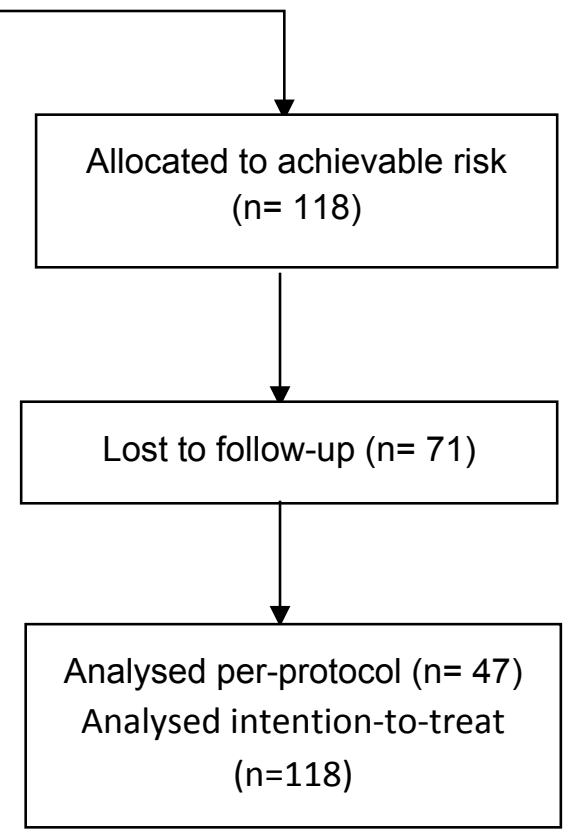

Randomized $(n=355)$ 


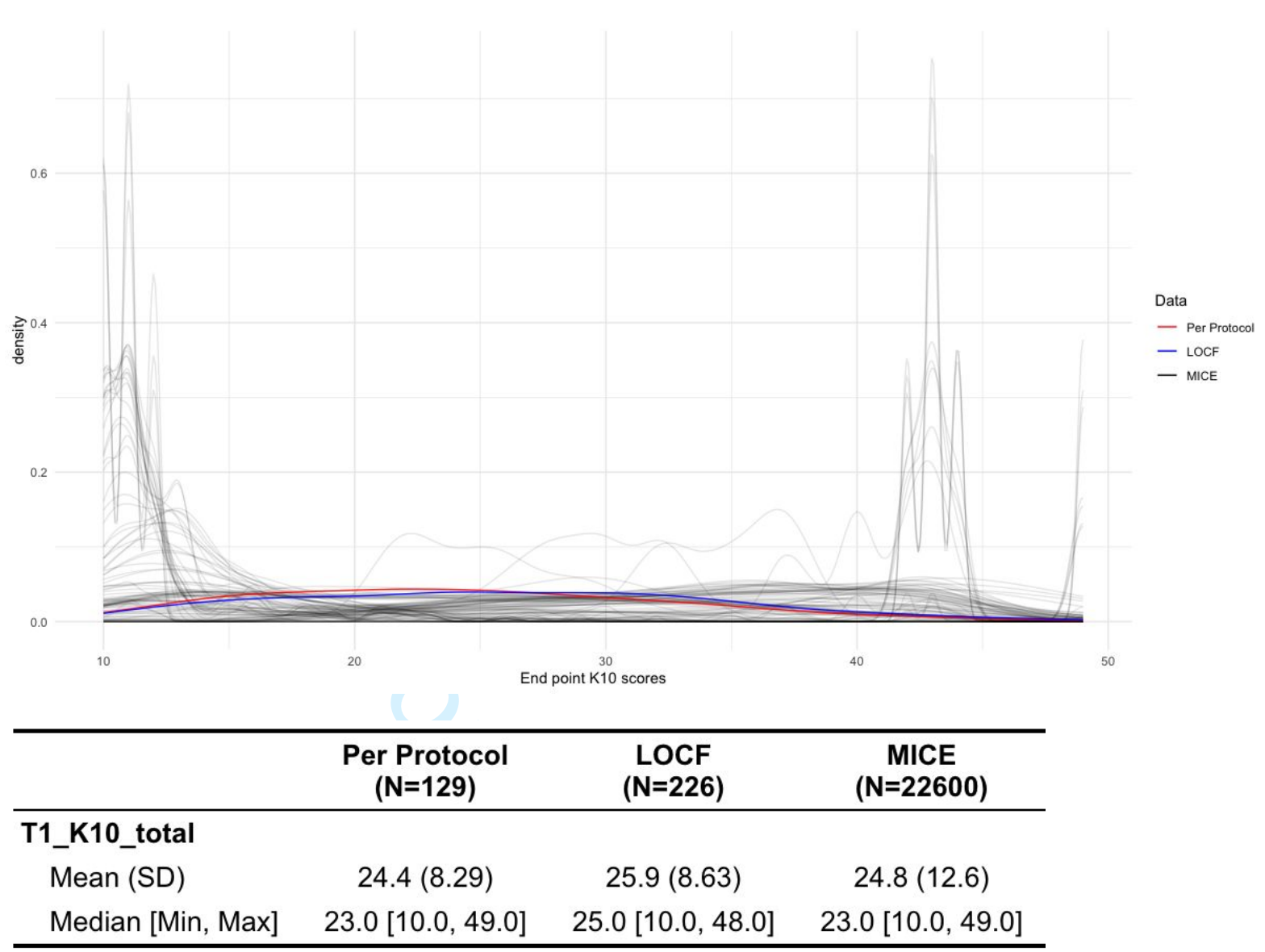

Figure 3. End point K10 scores as observed per-protocol, LOCF, and predicted by MICE. 
Early Intervention Psychiatry

Page 18 of 24

$$
\begin{aligned}
& 1 \\
& 2 \\
& 3 \\
& 4 \\
& 5 \\
& 6 \\
& 7 \\
& 8 \\
& 9 \\
& 10 \\
& 11 \\
& 12 \\
& 13 \\
& 14 \\
& 15 \\
& 16 \\
& 17 \\
& 18 \\
& 19 \\
& 20 \\
& 21 \\
& 22 \\
& 23 \\
& 24 \\
& 25 \\
& 26 \\
& 27 \\
& 28 \\
& 29 \\
& 30 \\
& 31 \\
& 32 \\
& 33 \\
& 34 \\
& 35 \\
& 36 \\
& 37 \\
& 38 \\
& 39 \\
& 40 \\
& 41 \\
& 42 \\
& 43 \\
& 44 \\
& 45 \\
& 46 \\
& 47 \\
& 48 \\
& 49 \\
& 50 \\
& 51 \\
& 52 \\
& 53 \\
& 54 \\
& 55 \\
& 56 \\
& 57 \\
& 58 \\
& 59 \\
& 60
\end{aligned}
$$

Figure 4. Change in K10 mean score over time across the groups.

1 
Table 1. Items in the mental ill-health risk assessment

\begin{tabular}{|c|c|}
\hline Women & Men \\
\hline Age & Age \\
\hline $\begin{array}{l}\text { Being from an Aboriginal and/or Torres Strait } \\
\text { Islander background }\end{array}$ & Being a carer $\star$ \\
\hline Satisfaction with the hours worked $\star$ & $\begin{array}{l}\text { Agree with the statement 'I have lot of } \\
\text { freedom to decide at work' } \star\end{array}$ \\
\hline Satisfaction with employment opportunities $\star$ & $\begin{array}{l}\text { Doing physical activity } 3 \text { or more times per } \\
\text { week } \star\end{array}$ \\
\hline History of common mental disorders & $\begin{array}{l}\text { Drinking between } 1 \text { and } 4 \text { drinks per week } \\
\text { (ref. none) } \star \\
\text { Drinking more than } 4 \text { drinks per week (ref. } \\
\text { none) } \star\end{array}$ \\
\hline Satisfaction with health $\star$ & History of common mental disorders \\
\hline Agree with the statement 'I am pushed around' $\star$ & Satisfaction with health $\star$ \\
\hline \multirow[t]{6}{*}{$\begin{array}{l}\text { Agree with the statement 'I don't have anyone that I } \\
\text { can confide in } \star\end{array}$} & Satisfaction with the neighbourhood $\star$ \\
\hline & $\begin{array}{l}\text { Neutral satisfaction with partner (ref. } \\
\text { satisfied with partner) Dissatisfied with } \\
\text { partner (ref. satisfied with partner) Not } \\
\text { having a partner (ref. satisfied with partner) } \\
\star\end{array}$ \\
\hline & $\begin{array}{l}\text { Neutral satisfaction with the way tasks are } \\
\text { divided at home (ref. satisfied) Dissatisfied } \\
\text { with the way tasks are divided at home (ref. } \\
\text { satisfied) Not having to divide tasks at } \\
\text { home (ref. satisfied) } \star\end{array}$ \\
\hline & $\begin{array}{l}\text { Agree with the statement 'I don't have } \\
\text { anyone that I can confide in' } \star\end{array}$ \\
\hline & $\begin{array}{l}\text { Agree with the statement 'I am pushed } \\
\text { around' } \star\end{array}$ \\
\hline & English as a second language \\
\hline
\end{tabular}


Table 2. Demographic and baseline characteristics of participants.

\begin{tabular}{|c|c|c|c|c|}
\hline & $\begin{array}{l}\text { Control } \\
(n=118)\end{array}$ & $\begin{array}{l}\text { Current risk } \\
(n=119)\end{array}$ & $\begin{array}{l}\text { Achievable risk } \\
(n=118)\end{array}$ & Difference \\
\hline Age (SD) & $\begin{array}{l}30.92 \\
(11.87)\end{array}$ & $31.64(13.16)$ & $33.14(12.80)$ & $\mathrm{F}_{2,352}=.950, p=.388$ \\
\hline Gender & & & & $x^{2}=2.359, p=.308$ \\
\hline Female & $85(72 \%)$ & $81(68 \%)$ & $74(63 \%)$ & \\
\hline Male & $33(28 \%)$ & $38(32 \%)$ & $44(37 \%)$ & \\
\hline Aboriginal or Torres Strait Islander & $6(5 \%)$ & $3(2.5 \%)$ & $1(1 \%)$ & \\
\hline English as second language & $17(14 \%)$ & $16(13 \%)$ & $20(17 \%)$ & $x^{2}=.611, p=.737$ \\
\hline Education & & & & $x^{2}=1.949, p=.745$ \\
\hline High school & $38(32 \%)$ & $36(30 \%)$ & $32(27 \%)$ & \\
\hline Trade or other certificate & $30(25 \%)$ & $37(31 \%)$ & $32(27 \%)$ & \\
\hline University degree & $50(43 \%)$ & $46(39 \%)$ & $54(46 \%)$ & \\
\hline \multicolumn{5}{|l|}{ Work status } \\
\hline Not working & $26(22 \%)$ & $26(22 \%)$ & $17(14 \%)$ & $x^{2}=5.776, p=.216$ \\
\hline Part time paid work & $43(36 \%)$ & $48(40 \%)$ & $40(34 \%)$ & \\
\hline Full time paid work & $49(42 \%)$ & $45(38 \%)$ & $61(52 \%)$ & \\
\hline In relationship & $71(60 \%)$ & $67(56 \%)$ & $67(57 \%)$ & $x^{2}=.431, p=.806$ \\
\hline Previous poor mental health & $94(80 \%)$ & $92(77 \%)$ & $93(79 \%)$ & $x^{2}=.200, p=.905$ \\
\hline K10 score (SD) & $\begin{array}{l}25.95 \\
(8.054)\end{array}$ & $26.77(9.19)$ & $26.19(8.60)$ & $F_{2,352}=.287, p=.751$ \\
\hline \multicolumn{5}{|l|}{ Risk score (SD) } \\
\hline Male & $.48(.30)$ & $.40(.26)$ & $.50(.26)$ & $F_{2,112}=1.466, p=.235$ \\
\hline Female & $.58(.25)$ & $.58(.24)$ & $.55(.26)$ & $\mathrm{F}_{2,237}=.528, p=.590$ \\
\hline \multicolumn{5}{|l|}{ Risk category } \\
\hline Low to average & $26(22 \%)$ & $26(22 \%)$ & $24(20 \%)$ & $x^{2}=.121, p=.941$ \\
\hline High & $92(78 \%)$ & $93(78 \%)$ & $94(80 \%)$ & \\
\hline
\end{tabular}


Table 3. Mean K10 scores across groups from baseline to follow up (per protocol)

\begin{tabular}{llll}
\hline K10 & Current risk $(\mathbf{n}=\mathbf{4 4})$ & Achievable risk $(\mathbf{n}=\mathbf{4 7})$ & Control $(\mathbf{n = 3 8})$ \\
\hline Baseline (SD) & $27.07(8.73)$ & $26.89(9.17)$ & $27.34(7.73)$ \\
4-week follow up (SD) & $24.59(6.59)$ & $24.19(9.72)$ & $24.55(8.37)$ \\
Mean change (SD) & $-2.48(7.09)$ & $-2.70(5.64)$ & $-2.79(8.25)$ \\
$\begin{array}{l}\text { Estimated mean change } \\
\text { (95\% Confidence Intervals) }\end{array}$ & $-2.39(-4.27--.51)$ & $-2.77(-4.59--.96)$ & $-2.81(-4.83--.78)$ \\
\end{tabular}


Table 4: Accuracy of perceived risk

\begin{tabular}{llll}
\hline & $\begin{array}{l}\text { Current risk group } \\
\mathbf{N}(\%)\end{array}$ & $\begin{array}{l}\text { Achievable risk group } \\
\mathbf{N}(\%)\end{array}$ & $\begin{array}{l}\text { Control } \\
\mathbf{N}(\%)\end{array}$ \\
\hline Accurate & $22(50 \%)$ & $15(32 \%)$ & $6(16 \%)$ \\
Overestimate risk & $12(27 \%)$ & $15(32 \%)$ & $11(30 \%)$ \\
Underestimate risk & $10(23 \%)$ & $17(36 \%)$ & $20(54 \%)$ \\
\hline
\end{tabular}


Supplementary Table 1: Baseline demographic and clinical characteristics of those who dropped out and completed 4 week follow up.

\begin{tabular}{|c|c|c|c|}
\hline & $\begin{array}{l}\text { Dropped out } \\
(n=226)\end{array}$ & $\begin{array}{l}\text { Remained in } \\
\text { trial }(n=129)\end{array}$ & Significance \\
\hline Age (SD) & $30.54(11.80)$ & $34.26(13.67)$ & $t_{1,353}=-2.69, p=.007$ \\
\hline Gender & & & $X^{2}=.877, p=.349$ \\
\hline Female & $149(65.6 \%)$ & $91(37.9 \%)$ & \\
\hline Male & $78(34.4 \%)$ & $37(28.9 \%)$ & \\
\hline Education & & & $x^{2}=3.354, p=.187$ \\
\hline High school & $75(33.2 \%)$ & $31(24 \%)$ & \\
\hline Trade or other certificate & $61(27 \%)$ & $38(29.5 \%)$ & \\
\hline University degree & 90 (39.8\%) & $60(46.5 \%)$ & \\
\hline \multicolumn{4}{|l|}{ Work status } \\
\hline Not working & $38(16.8 \%)$ & $31(24 \%)$ & $x^{2}=2.780, p=.249$ \\
\hline Part time paid work & $87(38.5 \%)$ & $44(34.1 \%)$ & \\
\hline Full time paid work & $101(44.7 \%)$ & $54(41.9 \%)$ & \\
\hline In relationship & $123(54.4 \%)$ & $82(64.6 \%)$ & $X^{2}=2.450, p=.118$ \\
\hline Previous poor mental health & $175(77.4 \%)$ & $104(80.6 \%)$ & $X^{2}=.324, p=.569$ \\
\hline K10 score (SD) & $25.86(8.63)$ & $27.09(8.55)$ & $\begin{array}{l}t_{1,353}=-1.29 \\
p=.197\end{array}$ \\
\hline \multicolumn{4}{|l|}{ Risk category } \\
\hline Low to average & $48(21.2 \%)$ & $28(21.7 \%)$ & $x^{2}=.000, p=1.000$ \\
\hline High & $178(78.8 \%)$ & $101(78.3 \%)$ & \\
\hline
\end{tabular}

